\title{
Synergistic Removal of Zinc and Copper in Greenhouse Waste Effluent by Struvite
}

Ashaki A. Rouff,* Marlon V. Ramlogan and Alon Rabinovich

Department of Earth and Environmental Sciences, Rutgers University, 101 Warren St., Newark, New Jersey 07102, USA

*Corresponding author contact information:

Address: Department of Earth and Environmental Sciences, Rutgers University, 101 Warren St., Newark, NJ 07102, USA.

Email: ashaki.rouff@rutgers.edu

Phone: (973) 353-2511

Fax: (973) 353-1965

Supporting Information: 8 Tables, 4 Figures, 13 pages 


\section{Composition of greenhouse waste}

Results from major cation, anion and trace element analysis of the greenhouse waste (GW) is presented below. Of the trace elements, $\mathrm{Cu}$ and $\mathrm{Zn}$ were detected in highest concentrations in GW solutions, and were detectable in the derived solids reacted for 1-26 d. Iron was the only other element with a concentration $>100 \mathrm{mg} / \mathrm{L}$ in the $\mathrm{GW}$ solution. The Fe concentrations of the 1, 7, and $26 \mathrm{~d}$ solids were $0,12.9$ and $26.3 \mathrm{mg} / \mathrm{kg}$. Due to the low loadings, Fe was not examined further.

Table S1. Major ion, trace element and nutrient composition of the GW solution

\begin{tabular}{lcc|lcc}
\hline $\begin{array}{l}\text { Major } \\
\text { Constituents }\end{array}$ & $\mathrm{mg} / \mathrm{L}$ & $\mathrm{mM}$ & $\begin{array}{l}\text { Trace } \\
\text { Elements }\end{array}$ & $\mu \mathrm{g} / \mathrm{L}$ & $\mu \mathrm{M}$ \\
\hline $\mathrm{Mg}$ & 19 & 0.79 & $\mathrm{Al}$ & 13 & 0.48 \\
$\mathrm{NH}_{4}{ }^{+}$ & 9.9 & 0.55 & $\mathrm{Ba}$ & 15.7 & 0.11 \\
$\mathrm{PO}_{4}{ }^{3-}$ & 85.7 & 0.90 & $\mathrm{Cu}$ & 151 & 2.38 \\
$\mathrm{Na}$ & 23.5 & 1.02 & $\mathrm{Fe}$ & 115.7 & 2.07 \\
$\mathrm{Ca}$ & 96.8 & 2.41 & $\mathrm{Mn}$ & 15.3 & 0.28 \\
$\mathrm{~K}$ & 70 & 1.79 & $\mathrm{Ni}$ & 14.7 & 0.25 \\
$\mathrm{Cl}^{-}$ & 8 & 0.23 & $\mathrm{~Pb}$ & 11.4 & 0.06 \\
$\mathrm{NO}_{3}{ }^{-}$ & 2436 & 39.29 & $\mathrm{Se}$ & 16.4 & 0.21 \\
$\mathrm{SO}_{4}{ }^{2-}$ & 190 & 1.98 & $\mathrm{Zn}$ & 686 & 10.49 \\
& & & & & \\
\hline
\end{tabular}

\section{Measurement of total organic carbon and specific ultraviolet absorbance at $254 \mathbf{n m}$}

Total organic carbon (TOC) concentration was measured by a direct colorimetric method. The sample was adjusted to $\mathrm{pH} 2$ and stirred to acidify and remove inorganic carbon as $\mathrm{CO}_{2}(\mathrm{~g})$. The sample was added to an acid digestion vial along with persulfate powder. An ampule with a $\mathrm{pH}$ indicator reagent was inserted into the primary vial which was then capped. The samples were heated at $103-105{ }^{\circ} \mathrm{C}$ for 2 hours during which organic carbon was acid digested to produce $\mathrm{CO}_{2}(\mathrm{~g})$, which then diffused into the inner ampule to react with the $\mathrm{pH}$ indicator. The extent of 
color change of the indicator was equivalent to the TOC concentration of the sample. After heating, the vials were cooled for 1 hour prior to analysis using a Hach DR3900 spectrophotometer. The sample absorbance was measured at 598 and $430 \mathrm{~nm}$ and the intensity corrected using a reagent blank (DI water), and correlated to the TOC concentration of potassium hydrogen phthalate (KHP) standards.

The absorbance at $254 \mathrm{~nm}$ was measured using an Agilent Cary 300 spectrophotometer. This was divided by the organic carbon concentration and multiplied by 100 to determine the specific ultraviolet absorbance (SUVA) in units of L/mg-m. The SUVA for the GW solution was calculated to be $3.5 \mathrm{~L} / \mathrm{mg}$-m which is within the range for naturally occurring fulvic acids (FA).

\section{Precipitation of struvite from greenhouse waste effluent}

Struvite was precipitated from greenhouse waste with the goal of assessing the association of metals and other constituents during mineralization. The GW solution was filtered to remove fractions $>0.45 \mu \mathrm{m}$ and analyzed for $\mathrm{Mg}, \mathrm{P}$ and $\mathrm{NH}_{3}-\mathrm{N}$ concentration. Both $\mathrm{Mg}$ and $\mathrm{P}$ were measured by inductively coupled plasma optical emission spectroscopy (ICP-OES) using a Perkin Elmer DV 5300 instrument, and $\mathrm{NH}_{3}-\mathrm{N}$ was analyzed using a Hach DR 5000 UltravioletVisible spectrophotometer (UV-VIS). Measured molar concentrations were $0.8 \mathrm{mM} \mathrm{Mg}, 0.9 \mathrm{mM}$ $\mathrm{P}$ and $0.6 \mathrm{mM} \mathrm{NH}_{3}-\mathrm{N}$ (Table S1). Based on these concentrations the GW solution was treated to not only induce struvite precipitation, but also to generate sufficient solid for subsequent analysis. Commercial struvite was added as seeding material to the filtered GW at a loading of $0.1 \mathrm{~g} / \mathrm{L}$ and the aqueous $\mathrm{Mg}$ and $\mathrm{P}$ concentrations were adjusted to $17 \mathrm{mM}$ using stock solutions of $\left(\mathrm{NH}_{4}\right)_{2} \mathrm{HPO}_{4}$ and $\mathrm{MgCl}_{2}$. This ensured oversaturation and precipitation of struvite. The precipitate (GW PPT) was recovered after $24 \mathrm{~h}$ by filtering the entire solution volume, and was 
left to air dry at room temperature for further analysis. The GW PPT solid was analyzed as described in the main text for solids from GW and sodium nitrate (NN) solutions.

\section{Metal speciation in greenhouse waste and sodium nitrate solutions}

Visual Minteq was used with the default thermodynamic database to calculate the speciation of both $\mathrm{Cu}$ and $\mathrm{Zn}$ in $\mathrm{GW}$ and $\mathrm{NN}$ solutions. The default parameters were used for dissolved organics, taking into consideration that these parameters may not necessarily be representative of the organics in the GW solution.

Table S2. Speciation of $\mathrm{Zn}$ and $\mathrm{Cu}$ in $\mathrm{GW}$ and $\mathrm{NN}$ solutions calculated at pH 7.

\begin{tabular}{|c|c|c|c|c|}
\hline Component & \multicolumn{2}{|c|}{ GW solutions } & \multicolumn{2}{|c|}{ NN solutions } \\
\hline $\mathrm{Zn}$ & Species & $\%$ Total & Species & $\%$ Total \\
\hline & $\begin{array}{l}\mathrm{Zn}^{2+} \\
\mathrm{Zn} \mathrm{DOM} \\
\mathrm{ZnHPO}_{4}{ }^{0} \\
\mathrm{ZnSO}_{4}{ }^{0} \\
\mathrm{ZnNO}_{3}{ }^{+} \\
\mathrm{ZnOH}^{+} \\
\mathrm{Zn}\left(\mathrm{SO}_{4}\right)_{2}{ }^{2-} \\
\mathrm{Zn}\left(\mathrm{OH}_{2}{ }^{0}\right. \\
\mathrm{ZnNH}_{3}{ }^{2+} \\
\mathrm{ZnCl}^{+} \\
\mathrm{Zn}\left(\mathrm{NO}_{3}\right)_{2}{ }^{0}\end{array}$ & $\begin{array}{c}61.34 \\
16.03 \\
12.87 \\
6.06 \\
3.12 \\
0.38 \\
0.09 \\
0.04 \\
0.03 \\
0.02 \\
0.02\end{array}$ & $\begin{array}{l}\mathrm{Zn}^{2+} \\
\mathrm{ZnNO}_{3}{ }^{+} \\
\mathrm{ZnOH}^{+} \\
\mathrm{Zn}\left(\mathrm{NO}_{3}\right)_{2}{ }^{0} \\
\mathrm{Zn}\left(\mathrm{OH}_{2}\right)^{0} \\
\mathrm{ZnSO}_{4}{ }^{0}\end{array}$ & $\begin{array}{l}91.00 \\
8.40 \\
0.44 \\
0.10 \\
0.04 \\
0.02\end{array}$ \\
\hline $\mathrm{Cu}$ & $\begin{array}{l}\mathrm{Cu} \mathrm{DOM} 1 \\
\mathrm{CuHPO}_{4}{ }^{0} \\
\mathrm{Cu}^{2+} \\
\mathrm{CuOH}^{+} \\
\mathrm{CuSO}_{4}{ }^{0} \\
\mathrm{CuNO}_{3}{ }^{+} \\
\mathrm{CuNH}_{3}{ }^{2+} \\
\mathrm{Cu}(\mathrm{OH})_{2}{ }^{0}\end{array}$ & $\begin{array}{l}70.43 \\
14.54 \\
10.73 \\
2.08 \\
1.11 \\
0.69 \\
0.38 \\
0.03\end{array}$ & $\begin{array}{l}\mathrm{Cu}^{2+} \\
\mathrm{CuOH}^{+} \\
\mathrm{CuNO}_{3}{ }^{+} \\
\mathrm{Cu}_{2}(\mathrm{OH})_{2}{ }^{2+} \\
\mathrm{Cu}(\mathrm{OH})_{2}{ }^{0} \\
\mathrm{Cu}\left(\mathrm{NO}_{3}\right)_{2}{ }^{0} \\
\mathrm{CuSO}_{4}{ }^{0}\end{array}$ & $\begin{array}{l}78.44 \\
11.89 \\
9.12 \\
0.29 \\
0.17 \\
0.07 \\
0.02\end{array}$ \\
\hline
\end{tabular}




\section{EXAFS Analysis}

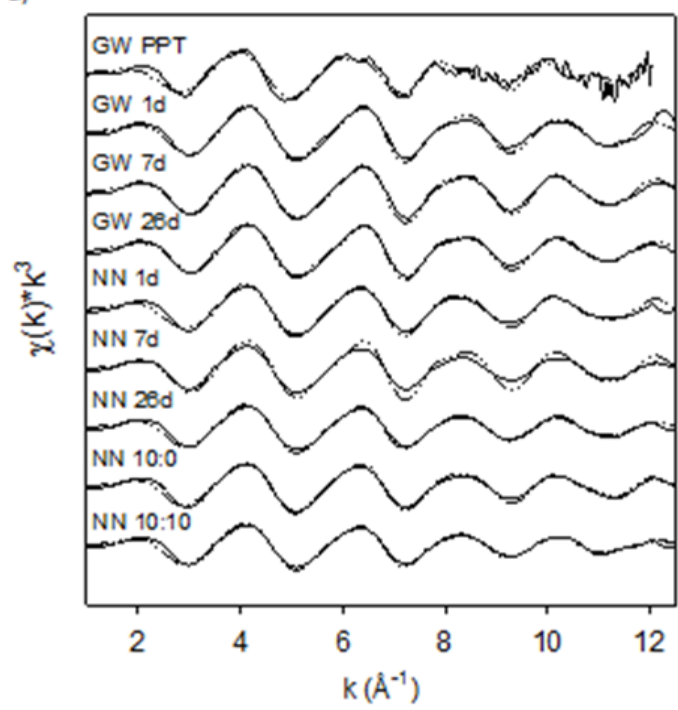

b)

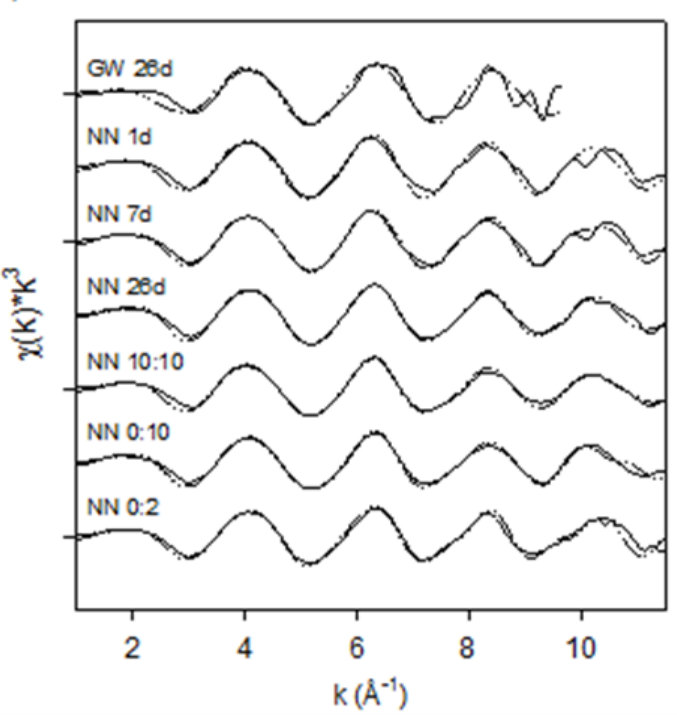

Figure S1. Experimental chi functions (solid lines) and fits to the data (dashed lines) collected at: a) the $\mathrm{Zn} \mathrm{K}$-edge and b) the $\mathrm{Cu}$ K-edge; for solids recovered from $\mathrm{GW}$ and $\mathrm{NN}$ solutions.

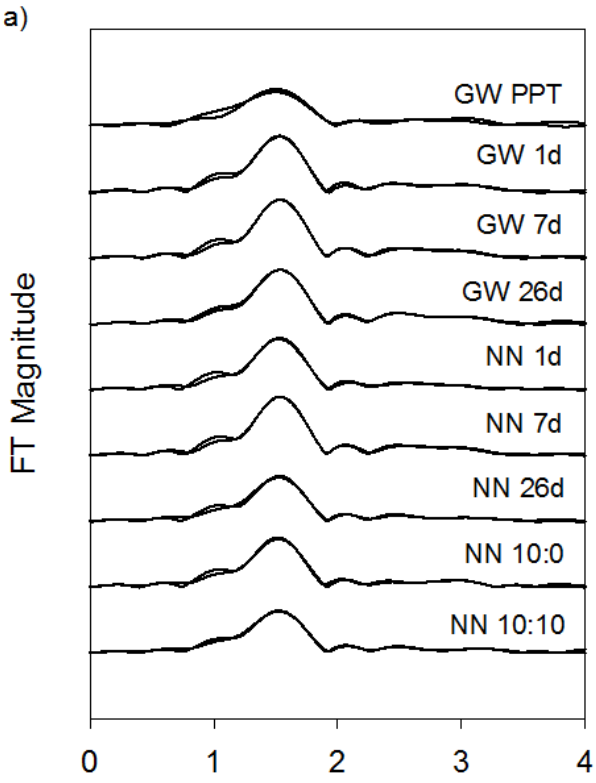

(A)

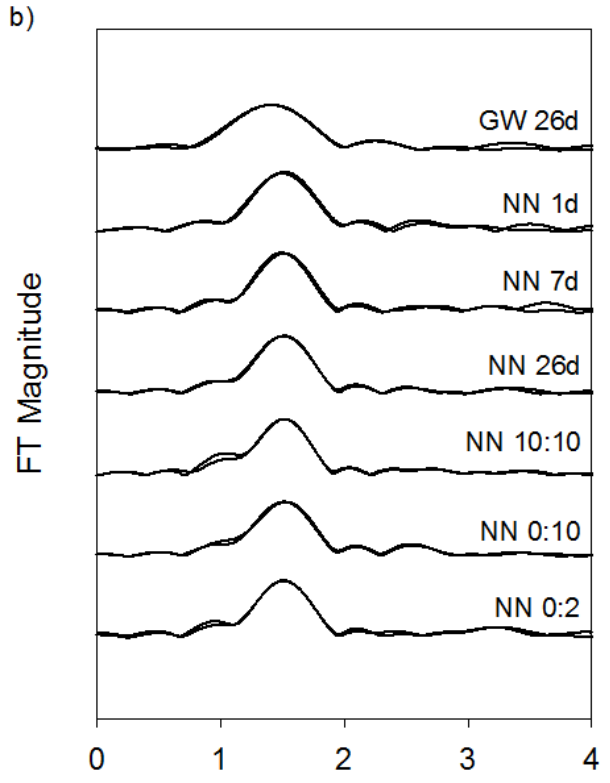

(A)

Figure S2. Fourier transformed radial distribution functions and fits to the data collected at: a) the $\mathrm{Zn} \mathrm{K}$-edge and b) the $\mathrm{Cu}$ K-edge; for solids recovered from GW and NN solutions. 
Table S3. Extended Zn EXAFS fit results to data for solids recovered from GW and NN solutions reacted for 1,7 or $26 \mathrm{~d}$ and for the GW PPT solid. Alternate fits for the GW $26 \mathrm{~d}$ and NN $7 \mathrm{~d}$ solids are in italics.

\begin{tabular}{|c|c|c|c|c|c|c|c|c|c|c|c|c|}
\hline & \multicolumn{6}{|c|}{ GW Solutions } & \multicolumn{6}{|c|}{ 0.1 M NN Solutions } \\
\hline & Shell & ${ }^{\mathrm{a}} \mathrm{CN}$ & ${ }^{\mathrm{b}} \mathrm{R}(\AA)$ & ${ }^{c} \sigma^{2}\left(\AA^{2}\right)$ & $\mathrm{E}_{0}(\mathrm{eV})$ & $\mathrm{R}$-factor & Shell & ${ }^{\mathrm{a}} \mathrm{CN}$ & ${ }^{\mathrm{b}} \mathrm{R}(\AA)$ & ${ }^{c} \sigma^{2}\left(\AA^{2}\right)$ & $\mathrm{E}_{0}(\mathrm{eV})$ & $\mathrm{R}$-factor \\
\hline \multirow[t]{4}{*}{$\mathrm{Zn}: 1 \mathrm{~d}$} & $\mathrm{O}$ & 4 & 1.95 & 0.004 & 3.618 & 0.0077 & $\mathrm{O}$ & 4 & 1.95 & 0.005 & 2.78 & 0.0066 \\
\hline & $\mathrm{P}$ & 1 & 3.06 & 0.011 & & & $\mathrm{Zn}$ & 1 & 3.25 & 0.007 & & \\
\hline & $\mathrm{Zn}$ & 1 & 3.30 & 0.009 & & & $\mathrm{P}$ & 1 & 3.58 & 0.004 & & \\
\hline & $\mathrm{O}$ & 2 & 3.74 & 0.006 & & & & & & & & \\
\hline \multirow[t]{8}{*}{$\mathrm{Zn}: 7 \mathrm{~d}$} & $\mathrm{O}$ & 4 & 1.95 & 0.004 & 4.49 & 0.0054 & $O$ & 4 & 1.95 & 0.006 & 3.19 & 0.0055 \\
\hline & $\mathrm{P}$ & 1 & 3.09 & 0.007 & & & $P$ & 1 & 3.11 & 0.023 & & \\
\hline & $\mathrm{Zn}$ & 1 & 3.28 & 0.010 & & & $Z n$ & 1 & 3.28 & 0.010 & & \\
\hline & $\mathrm{O}$ & 2 & 3.74 & 0.006 & & & $O$ & 2 & 3.75 & 0.006 & & \\
\hline & & & & & & & $\mathrm{O}$ & 4 & 1.95 & 0.006 & 3.20 & 0.0065 \\
\hline & & & & & & & $\mathrm{Zn}$ & 1 & 3.25 & 0.008 & & \\
\hline & & & & & & & $\mathrm{Cu}$ & 1 & 3.41 & 0.010 & & \\
\hline & & & & & & & $\mathrm{O}$ & 1 & 3.74 & 0.010 & & \\
\hline \multirow[t]{8}{*}{ Zn: 26d } & $O$ & 4 & 1.95 & 0.005 & 4.53 & 0.0065 & $\mathrm{O}$ & 4 & 1.95 & 0.006 & 2.82 & 0.0058 \\
\hline & $P$ & 1 & 3.08 & 0.011 & & & $\mathrm{Zn}$ & 1 & 3.24 & 0.008 & & \\
\hline & $Z n$ & 1 & 3.23 & 0.005 & & & $\mathrm{Cu}$ & 1 & 3.40 & 0.009 & & \\
\hline & $\mathrm{Cu}$ & 1 & 3.39 & 0.005 & & & $\mathrm{O}$ & 1 & 3.75 & 0.010 & & \\
\hline & $\mathrm{O}$ & 4 & 1.95 & 0.005 & 4.69 & 0.0054 & & & & & & \\
\hline & $\mathrm{P}$ & 1 & 3.07 & 0.006 & & & & & & & & \\
\hline & $\mathrm{Zn}$ & 1 & 3.32 & 0.010 & & & & & & & & \\
\hline & $\mathrm{O}$ & 2 & 3.72 & 0.009 & & & & & & & & \\
\hline \multirow[t]{2}{*}{ PPT } & $\mathrm{O}$ & 4.5 & 1.98 & 0.008 & 0.63 & 0.0325 & & & & & & \\
\hline & $\mathrm{Zn}$ & 1 & 3.26 & 0.005 & & & & & & & & \\
\hline
\end{tabular}


Table S4. Extended Cu EXAFS fit results to data for solids recovered from GW and NN solutions reacted for 1,7 or $26 \mathrm{~d}$.

\begin{tabular}{|c|c|c|c|c|c|c|c|c|c|c|c|c|}
\hline & \multicolumn{6}{|c|}{ GW Solutions } & \multicolumn{6}{|c|}{ 0.1 M NN Solutions } \\
\hline & Shell & ${ }^{\mathrm{a}} \mathrm{CN}$ & ${ }^{\mathrm{b}} \mathrm{R}(\AA)$ & ${ }^{c} \sigma^{2}\left(\AA^{2}\right)$ & $\mathrm{E}_{0}(\mathrm{eV})$ & R-factor & Shell & ${ }^{\mathrm{a}} \mathrm{CN}$ & ${ }^{\mathrm{b}} \mathrm{R}(\AA)$ & ${ }^{\mathrm{c}} \sigma^{2}\left(\AA^{2}\right)$ & $\mathrm{E}_{0}(\mathrm{eV})$ & R-factor \\
\hline \multirow[t]{3}{*}{$\mathrm{Cu}: 1 \mathrm{~d}$} & & & & & & & $\mathrm{O}$ & 4 & 1.96 & 0.003 & -1.12 & 0.0131 \\
\hline & & & & & & & $\mathrm{P}$ & 2 & 3.28 & 0.019 & & \\
\hline & & & & & & & $\mathrm{Cu}$ & 2 & 3.35 & 0.013 & & \\
\hline \multirow[t]{3}{*}{$\mathrm{Cu}: 7 \mathrm{~d}$} & & & & & & & $\mathrm{O}$ & 4 & 1.96 & 0.004 & 0.02 & 0.0180 \\
\hline & & & & & & & $\mathrm{P}$ & 2 & 3.28 & 0.011 & & \\
\hline & & & & & & & $\mathrm{Cu}$ & 1 & 3.33 & 0.006 & & \\
\hline \multirow[t]{4}{*}{$\mathrm{Cu}: 26 \mathrm{~d}$} & $\mathrm{O}$ & 4 & 1.92 & 0.003 & -5.94 & 0.0028 & $\mathrm{O}$ & 4 & 1.96 & 0.004 & 0.24 & 0.0047 \\
\hline & & & & & & & $\mathrm{P}$ & 1 & 3.16 & 0.009 & & \\
\hline & & & & & & & $\mathrm{Zn}$ & 1 & 3.48 & 0.010 & & \\
\hline & & & & & & & $\mathrm{O}$ & 4 & 3.68 & 0.010 & & \\
\hline
\end{tabular}


Table S5. Extended $\mathrm{Zn}$ and $\mathrm{Cu}$ EXAFS fit results to data for solids recovered from $\mathrm{NN}$ solutions reacted for $1 \mathrm{~d}$ at variable $\mathrm{Zn}: \mathrm{Cu}$ ratios.

\begin{tabular}{|c|c|c|c|c|c|c|c|c|c|c|c|c|}
\hline \multirow[b]{2}{*}{$\mathrm{Zn}: \mathrm{Cu}$} & \multicolumn{6}{|c|}{ Zn EXAFS } & \multicolumn{6}{|c|}{$\mathrm{Cu}$ EXAFS } \\
\hline & Shell & ${ }^{\mathrm{a}} \mathrm{CN}$ & ${ }^{\mathrm{b}} \mathrm{R}(\AA)$ & ${ }^{c} \sigma^{2}\left(\AA^{2}\right)$ & $\mathrm{E}_{0}(\mathrm{eV})$ & R-factor & Shell & ${ }^{\mathrm{a}} \mathrm{CN}$ & ${ }^{\mathrm{b}} \mathrm{R}(\AA)$ & ${ }^{c} \sigma^{2}\left(\AA^{2}\right)$ & $\mathrm{E}_{0}(\mathrm{eV})$ & R-factor \\
\hline \multirow[t]{3}{*}{ 10:0 } & $\mathrm{O}$ & 4 & 1.95 & 0.005 & 1.98 & 0.0096 & & & & & & \\
\hline & $\mathrm{Zn}$ & 1 & 3.27 & 0.008 & & & & & & & & \\
\hline & $\mathrm{O}$ & 1 & 3.76 & 0.007 & & & & & & & & \\
\hline \multirow[t]{4}{*}{$10: 10$} & $\mathrm{O}$ & 4 & 1.95 & 0.007 & 2.77 & 0.0043 & $\mathrm{O}$ & 4 & 1.95 & 0.005 & -1.91 & 0.0061 \\
\hline & $\mathrm{Zn}$ & 1 & 3.23 & 0.008 & & & $\mathrm{P}$ & 2 & 3.19 & 0.008 & & \\
\hline & $\mathrm{Cu}$ & 1 & 3.39 & 0.007 & & & $\mathrm{Cu}$ & 1 & 3.23 & 0.010 & & \\
\hline & $\mathrm{O}$ & 1 & 3.75 & 0.015 & & & $\mathrm{O}$ & 2 & 3.77 & 0.006 & & \\
\hline \multirow[t]{4}{*}{$0: 10$} & & & & & & & $\mathrm{O}$ & 4 & 1.96 & 0.004 & -0.21 & 0.0052 \\
\hline & & & & & & & $\mathrm{P}$ & 2 & 3.20 & 0.007 & & \\
\hline & & & & & & & $\mathrm{Cu}$ & 1 & 3.25 & 0.005 & & \\
\hline & & & & & & & $\mathrm{O}$ & 2 & 3.79 & 0.004 & & \\
\hline \multirow[t]{3}{*}{$0: 2$} & & & & & & & $\mathrm{O}$ & 4 & 1.96 & 0.004 & -0.43 & 0.0098 \\
\hline & & & & & & & $\mathrm{P}$ & 1 & 3.29 & 0.003 & & \\
\hline & & & & & & & $\mathrm{Cu}$ & 2 & 3.36 & 0.008 & & \\
\hline
\end{tabular}




\section{X-ray Diffraction Spectroscopy}

All recovered solids were analyzed using a Bruker D8 Advance Eco, with a $\mathrm{Cu}$ anode (1.54£). Scans were collected over a range of $5-60^{\circ} 2 \theta$, in $0.1^{\circ} 2 \theta$ increment step sizes and a counting time of $1 \mathrm{~s}$ per step. Generally, the sample XRD patterns revealed the recovered solids were crystalline. Relative to MAP, changes in reflections are evident when interacting with $\mathrm{Zn}$ and $\mathrm{Cu}$. In the presence of $\mathrm{Zn}$ alone, the NN 10:0 pattern shows lower intensity of the three peaks centered at $15^{\circ} 2 \theta$ relative to the MAP standard, with all other peaks comparable to MAP. For the $\mathrm{Cu}$ only samples $\mathrm{NN} 0: 10$ and 0:2, changes in the intensity of peaks centered at 15,21 and 33 - $2 \theta$ are evident. Overall $\mathrm{Cu}$ has more of an impact on the XRD reflections, and thus crystal structure of struvite compared to $\mathrm{Zn}$.

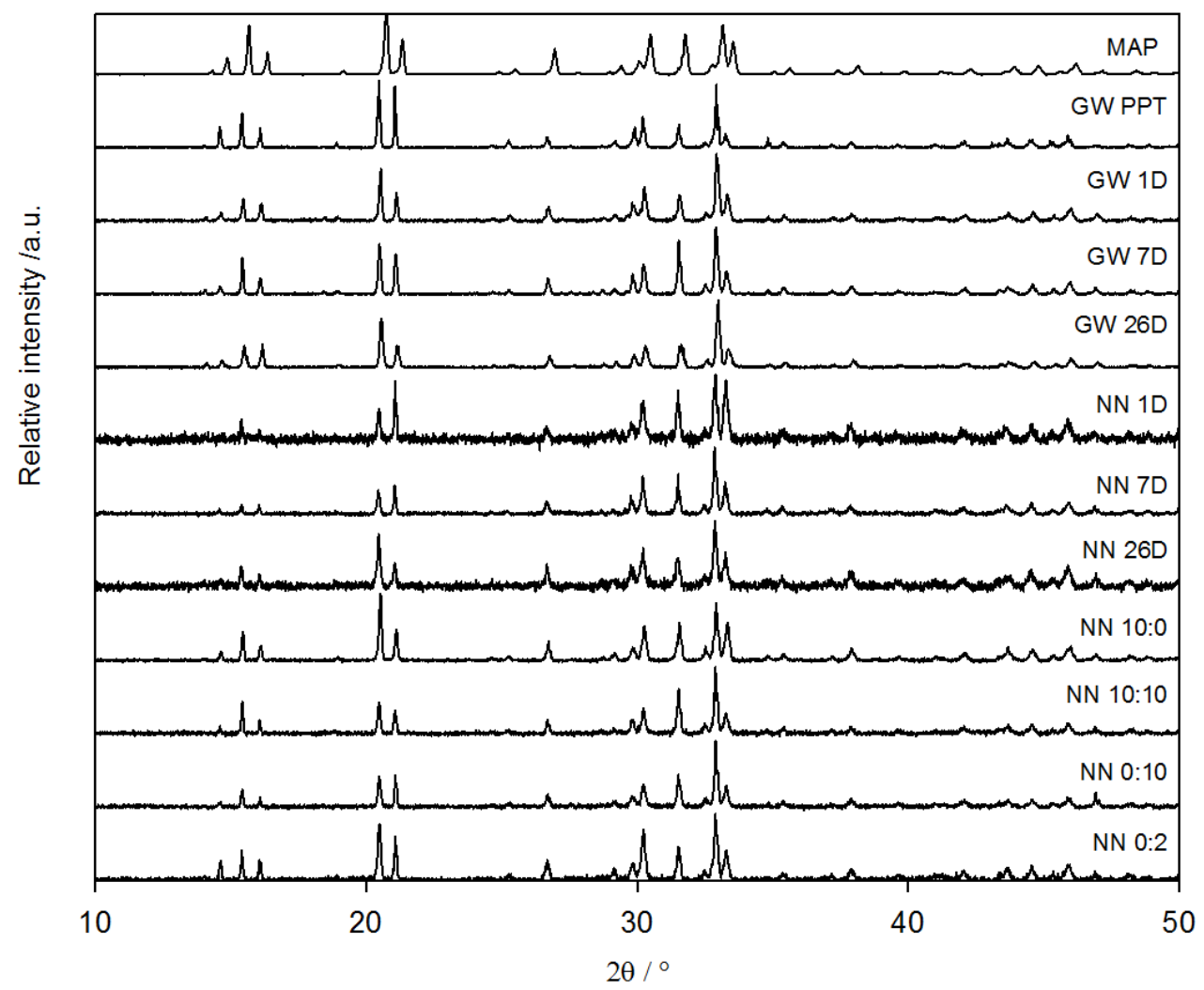

Figure S3. XRD patterns of solids recovered from GW and NN solutions and a struvite standard. 


\section{Sorption of Organics}

Experiments were designed to assess the sorption of dissolved organic carbon (DOC) with struvite. Potassium hydrogen phthalate (KHP) was added to $0.1 \mathrm{M} \mathrm{NaNO}_{3}$ solutions so that the initial DOC concentration was $50 \mathrm{mg} / \mathrm{L}$ as observed for the $\mathrm{GW}$ solutions. Struvite was added at a loading of $1 \mathrm{~g} / \mathrm{L}$ and the solutions reacted for 1,7 or $26 \mathrm{~d}$ as for $\mathrm{GW}$ and $\mathrm{NN}$ solutions. At the end of the reaction time DOC solutions were filtered and the solid allowed to air dry. Recovered solids were dissolved and analyzed for TOC by a colorimetric method using a HACH DR 3900 spectrophotometer, and the absorbance at $254 \mathrm{~nm}$ measured using an Agilent Cary 300 spectrophotometer as described above. The SUVA was calculated using the TOC measurement and the absorbance at $254 \mathrm{~nm}$. The measured TOC value was dilution corrected to determine the TOC loading of the solid. All solids were subject to FTIR analysis using a Perkin Elmer Spectrum 100 FTIR.

a)

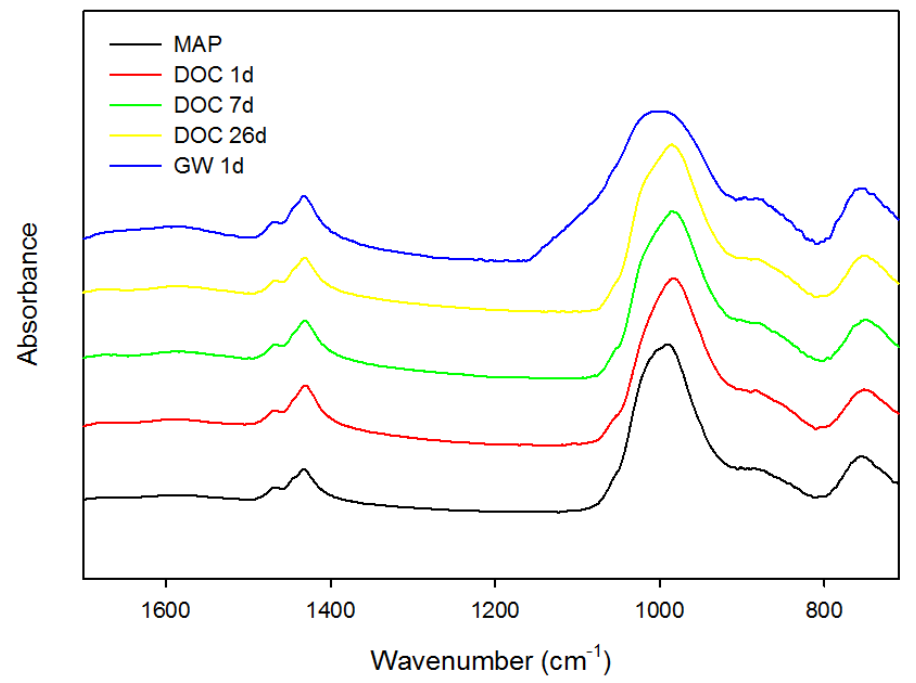

b)

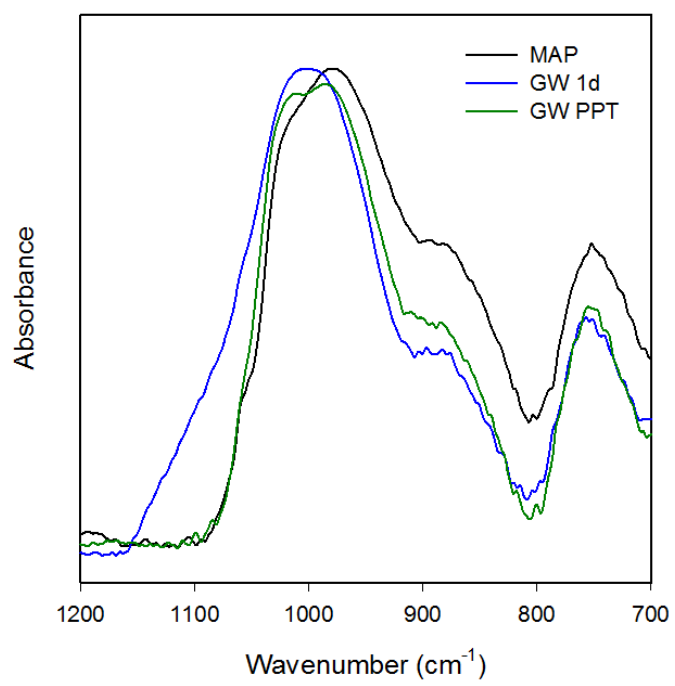

Figure S4. FTIR Spectra for a) solids from DOC solutions and unreacted MAP as compared to the GW 1d sample; b) unreacted MAP, GW 1d and GW PPT solids in the region of the phosphate band. 
Table S6. Measured TOC concentrations for GW and DOC samples, and SUVA values for GW samples.

\begin{tabular}{l|c|c|c}
\hline & DOC Solutions & \multicolumn{2}{|c}{ GW Solutions } \\
\hline Aqueous & TOC $(\mathrm{mg} / \mathrm{L})$ & TOC $(\mathrm{mg} / \mathrm{L})$ & SUVA (L/mg-m) \\
\hline & 50 & 50 & 3.5 \\
& & & \\
\hline Solid & TOC (mg/kg) & TOC (mg/kg) & SUVA (L/mg-m) \\
\hline 1d & 441 & 1825 & 11.7 \\
$7 \mathrm{~d}$ & 361 & 4041 & 13.5 \\
26d & 644 & 8806 & 11.2 \\
PPT & & 1721 & 21.4 \\
& & & \\
\hline
\end{tabular}

The FTIR spectra for solids from DOC solutions do not show band broadening in the $\sim 1060 \mathrm{~cm}^{-1}$ region as observed for the time-dependent GW samples (Figure S4). This may be an effect of concentration. The TOC content of solids derived from DOC solutions is approximately an order of magnitude lower than that of the equivalent GW solid (Table S3). This in turn may be due to several factors. Most likely the model organic KHP used in the DOC solutions is not representative of the organic carbon present in the GW solution, both chemically and with respect to sorption capacity with struvite. Based on the SUVA value, the organics in the GW solution are likely FA, which would support this assumption. Furthermore, the chemical form of the sorbed organics is different from the dissolved organic in GW. The SUVA values for organics associated with the solids are higher compared to the GW solution, indicating a higher degree of aromaticity. Therefore there is some fractionation whereby organics with higher aromatic content preferentially sorb. Because all organics in the DOC solutions are the same, fractionation during sorption is not likely to be a factor.

Organic sorption may also be enhanced by metals, specifically $\mathrm{Cu}$, which are not present in DOC solutions. However, because metal loadings are 1-2 orders of magnitude lower than the 
TOC loadings this is suggestive of the presence of particularly $\mathrm{C}$ dense organics if sorption is facilitated by these complexes. The SUVA values for the sorbed organics in GW solids does indicate high aromaticity, but it is unclear if these are indeed metal-organic complexes. It is most feasible that the organics mostly sorb independently of the metals and metal-organic complexes remain in the dissolved phase. The FTIR spectrum for the GW PPT solid does not exhibit the broadening observed for other GW solids (Figure S4b). The TOC loading is slightly, though not significantly, lower than that of the GW 1d solid. However, the SUVA value, and thus aromatic content is almost double that of the other GW solids, and the mechanism of interaction may not be directly comparable because of differences in sample preparation. It is unclear if these factors account for the absence of the feature in the GW PPT sample. This, combined with results from TOC experiments means that the source of the broadening at $1060 \mathrm{~cm}^{-1}$ is inconclusive, and it is uncertain if this additional feature in the FTIR can be attributed solely to organic interaction.

\section{Simultaneous Thermal Analysis and Evolved Gas Analysis}

Table S7. Select results from simultaneous thermal analysis of GW and NN solids.

\begin{tabular}{l|ccc|ccc}
\hline \multirow{2}{*}{ Sample } & \multicolumn{3}{|c|}{ Thermogravimetric Analysis } & \multicolumn{3}{c}{ Differential Scanning Calorimetry } \\
& Mass Loss, \% & Onset, ${ }^{\circ} \mathrm{C}$ & DTG, ${ }^{\circ} \mathrm{C}$ & Onset, ${ }^{\circ} \mathrm{C}$ & Peak, ${ }^{\circ} \mathrm{C}$ & Area, J/g \\
& & & & & & \\
\hline MAP & 53.42 & 105.7 & 134.7 & 95.0 & 135.9 & 1506 \\
NN 1d & 51.36 & 104.3 & 131.9 & 91.6 & 137.1 & 1447 \\
NN 7d & 53.32 & 103.6 & 141.2 & 91.9 & 139.1 & 1451 \\
NN 26d & 51.93 & 102.3 & 136.0 & 91.1 & 135.3 & 1463 \\
GW 1d & 51.72 & 105.3 & 133.2 & 93.8 & 136.1 & 1453 \\
GW 7d & 49.27 & 102.7 & 134.1 & 91.6 & 135.2 & 1365 \\
GW 26d & 39.83 & 99.2 & 125.5 & 90.2 & 127.6 & 1181 \\
GW PPT & 54.19 & 103.8 & 136.6 & 92.3 & 136.2 & 1601 \\
& & & & & & \\
\hline
\end{tabular}


Table S8. FTIR absorbance in the Gram Schmidt (GS) curve and maximum temperature of release of identified gases.

\begin{tabular}{l|c|cccc}
\hline & & \multicolumn{5}{|c}{ Maximum Temperature of Gas Release, ${ }^{\circ} \mathrm{C}$} \\
Sample & GS Max, ${ }^{\circ} \mathrm{C}$ & $\mathrm{NH}_{3}(\mathrm{~g})$ & $\mathrm{H}_{2} \mathrm{O}(\mathrm{g})$ & $\mathrm{CO}(\mathrm{g})$ & $\mathrm{CO}_{2}(\mathrm{~g})$ \\
& & & & & \\
\hline MAP & 142.7 & 147 & 147 & - & - \\
NN 1d & 143.1 & 146 & 146 & - & - \\
NN 7d & 147.0 & 149 & 153 & - & - \\
NN 26d & 139.1 & 143 & 146 & - & - \\
GW 1d & 146.9 & 146 & 146 & 336 & - \\
GW 7d & 143.4 & 146 & 146 & 262 & - \\
GW 26d & 126.6 & 130 & 130 & 253 & 405 \\
GW PPT & 136.2 & 146 & 146 & 340 & - \\
& & & & & \\
\hline
\end{tabular}

